\title{
IDOSOS EM TEMPOS DA COVID
}

\author{
Neiva Junkes Hoepers \\ Susana Raquel Perico Pavei
}

DOI: http://dx.doi.org/10.18616/intcov23

A pandemia causada pela covid-19 ainda está em construção quanto aos seus padrões de tratamento. Mas sabe-se que sua infectividade e letalidade são muito significativas e com uma expressiva taxa de mortalidade.

A Organização Mundial da Saúde (OMS) (2020) divulga dados da covid-19 que apontam maior taxa de mortalidade entre as pessoas com 80 anos ou mais, dessa forma, reforçando as preocupações com a população idosa. Como também, coloca que o risco de morrer por causa da covid-19 aumenta com a idade, já que a maioria das mortes ocorrem em idosos, especialmente aqueles com comorbidades. Assim sendo, além das questões fisiopatológicas e epidemiológicas, deve ser discutido o impacto da pandemia covid-19 na saúde do idoso, família, profissionais de saúde e sociedade, principalmente no que se refere a saúde mental implicada pelo medo, ansiedade e pânico.

Atitudes e ações tomadas por todas as pessoas é a melhor prevenção para evitar que esse público adoeça gravemente, com risco de morte, mesmo que seu estado de saúde geral seja bom. Os cuidados devem ser redobrados, advertindo que nos momentos de ansiedade, medo e pânico, medidas básicas, práticas e seguras podem ajudar muito, como: lavar frequentemente as mãos com água e sabão ou utilizar álcool gel 70\% sempre que tocar em objetos ou em superfícies; não coçar, tocar ou esfregar as mão sujas nos olhos ou nariz; usar máscaras sempre que for sair ou conversar com alguém principalmente idosos em Instituições de Longas Permanência para Idosos; seguir o isolamento/distanciamento social em todos os espaços; ao tossir ou expirar, cobrir a boca com lenço umedecido ou o faça no braço sobre a roupa; evitar contato com outras pessoas, se apresentar sintomas, como: tosse, febre, dispneia e cansaço, ou ainda, sonolência excessiva. 
A Sociedade Brasileira de Geriatria e Gerontologia (SBGG) aborda a importância de cuidados redobrados com a saúde dos idosos em relação à covid-19 e diz que essa doença pode se manifestar de forma grave ou até fatal nessa faixa etária da população. A promoção e prevenção de doenças contribuem para maior segurança a essas pessoas com idade de 60 anos ou mais, como: cuidar bem da saúde, estar sempre bem hidratados, fazer a higienização das mãos com frequência, evitar contato com as pessoas que vêm de regiões com casos confirmados da doença e manter o calendário de vacinação em dia, dessa forma, proteger-se de outras infecções (SBGG, 2020).

A vivência da pandemia covid-19 ressignificou condutas, conhecimentos e aproximou a comunidade do meio científico, pois, para o controle, são necessárias mudanças comportamentais individuais e coletivas, porém, não unicamente durante o período de pandemia (HAMMERSCHMIDT; SANATANA, 2020).

A pandemia é um período árduo e com uma imensidão de informações e instrumentos variados de acesso, alguns sem confiabilidade. Essa discrepância de informações torna-se, por vezes, estressante, podendo causar doenças. A OMS preconiza o cuidado com a covid-19, mas também com o exagero de informações, muitas vezes, falsas.

Os aprendizados e os momentos de distanciamento social são medidas de precaução à saúde, com intenção de preservação e proteção; porém a autonomia e a independência do idoso são os pilares para um envelhecimento saudável. É essencial que as experiências propiciadas por esse turbulento momento de crise fortaleçam e preparem a sociedade para outras situações de tensão.

\section{REFERÊNCIAS}

HAMMERSCHMIDT, Karina Silveira de Almeida; SANTANA, Rosimere Ferreira. Saúde do idoso em tempos de pandemia covid-19. 2020. Disponível em http://docs.bvsalud.org/biblioref/2020/04/1095404/72849-288133-1-pb. pdf. Acesso em: 16 jun. 2020. 
SOCIEDADE BRASILEIRA DE GERIATRIA E GERONTOLOGIA ( $S B G G$ ). Portal virtual. 2020. Disponível em: https://sbgg.org.br/. Acesso em: 11 dez. 2020.

WORLD HEALTH ORGANIZATION (WHO). Novel Coronavirus (2019$n \mathrm{CoV}$ ) technical guidance, 2020. Geneva: WHO, 2020. Disponível em: https:// www.who.int/emergencies/diseases/novel-coronavirus-2019. Acesso em: 4 abr. 2020. 